\title{
A METÁFORA DO ESTRANGEIRO NO CONTEXTO DO ABSURDO MORAL NA OBRA DE ALBERT CAMUS
} The metaphor of The Stranger in the context of moral absurdity in Albert Camus's
work

Glaucer Ferreira Silva ${ }^{1}$

RESUMO: O presente estudo tem como meta debruçar-se sobre a obra de um dos mais significantes autores do século XX: Albert Camus. O autor propõe em seus textos uma aproximação entre o fazer literário e o rigor filosófico. Duas obras serão analisadas neste texto: $O$ Mito de Sísifo e $O$ estrangeiro. Ambas versam sobre o conceito camusiano de Absurdidade. $O$ fato literário foi à forma encontrada por Camus para expressar suas mais intimas angustias, vale ressaltar que sua produção se localiza no período da Segunda Guerra Mundial, o salto no absurdo seria a forma de se viver uma existência autêntica. Tal salto conduz o homem do absurdo à solidariedade, posto que quando não existe um modelo ético tolerável à relação de alteridade tira o homem do completo niilismo e da descrença em que o absurdo pode conduzi-lo. A metáfora do estrangeiro é o escopo no presente texto. Vale ressaltar que este estudo tem como objetivo investigar, a partir da produção camusiana, a relação entre homem e mundo, tendo como foco a confluência ética existente entre esses termos. Trata-se, portanto, de uma pesquisa de caráter bibliográfico que pretende minimizar a problemática moral e ética interligadas a um fato literário.

Palavras-chaves: Literatura. Absurdidade. Existencialismo. Estrangeiro. Filosofia

ABSTRACT: The present study has the goal of elaborating on the work of one of the most significant authors of the XX century: Albert Camus. The author proposes in his texts an approximation between the literary praxis and the philosophical rigor. Two pieces of his work will be analyzed in this text: The Mith of Sisyphus and The Stranger. Both approach the camusian concept of "Absurdity". The literary fact was the way found to express his most intimate anguishes, worth mentioning that their production happened during World War Two. The leap into the absurd would be the way to live an authentic existence. Such leap leads men from absurd to solidarity, since that when there is no bearable ethical model the otherness relation removes men from the complete nihilism and the incredulity which absurdity may lead them to. The metaphor of the stranger is the scope of the present text. It is worth mentioning the present study intends to investigate the relation between mankind and the world from a camusian perspective, focusing on the ethical convergence of these terms.

1 Graduando em Filosofia pela Universidade Estadual do Piauí - UESPI. E-mail: ferreiraglaucer85@gmail.com 
Therefore, this is a bibliographic research that aims to minimize the ethical and moral problematic connected to a literary fact.

Key-words: Literature. Absurdity. Existentialism. Stranger.

\section{LITERATURA E ABSURDIDADE}

A investigação existencial presente em O Mito de Sísifo (CAMUS, 2010, p.17) nos lança sobre o abismo denominado absurdidade ${ }^{2}$, trazendo como problema disparador, o divórcio entre homem e mundo via sobressalto, relação de tensão por excelência, contudo é um laço que une o rigor do fazer filosófico e a construção literária, visto que "começar a pensar é", adianta o autor, "começar a ser atormentado" (CAMUS, 2010, p 17), tal tormento é fruto da "gramática sangrenta da vida" (CAMUS, 2010), da denúncia de uma existência ilegítima pautada no hábito, no irrefletido (tal problemática está contida na chamada trilogia do absurdo que comporta as obras: $O$ Mito de Sísifo, O Estrangeiro e Calígula). O fenômeno do Homem Absurdo emerge da solidão, do individual, contudo tende à revolta, a solidariedade de uma força plural, uma dada conjunção de potências criativas que passam pela afirmação positiva da existência.

A absurdidade é fruto de uma dobra, assim como o fazer filosófico, um voltar-se para si. Reflexão esta que nos leva a compreender que a vida não possui um sentido prefixado, é necessário, portanto ter as rédeas desta, em um movimento que una tanto consciência de si como do outro, ou seja, da alteridade como norte para a saída da absurdidade para solidariedade ${ }^{3}$. "Enfim, é a consciência que ilustra a fratura entre o homem e o mundo" (CAMUS, 1965, p. 136) (tradução nossa). A literatura é a arma escolhida por Camus nesse combate, à esteira dos que the precederam, "os grandes romancistas são romancistas filósofos, ou seja, o contrário de escritores de teses. Vejam Balzac, Sade, Melville, Stendhal, Dostoievski, Proust, Malraux, Kafka, só para citar alguns" (CAMUS, 1965, p. 178) (tradução nossa), que

\footnotetext{
${ }^{2}$ A filosofia do absurdo proposta por Camus tem relação à tragicidade contida na existência humana. O homem absurdo, para o autor, é aquele que está diante de sua finitude e percebe a precariedade da existência.

${ }^{3}$ Esse movimento é parte de uma proposta bem mais ampla do autor, assim como este escreveu a trilogia do absurdo também dedicou-se à chamada trilogia da solidariedade, mas que não será amplamente debatida neste estudo.
} 
assim como Camus, souberam aliar o fazer filosófico com a criação ficcional, enlaçando, desse modo, a arte com o fazer filosofante.

Neste processo de espanto e desvelamento do pensamento maquinal que está contido na crítica que Albert Camus (1913-1960), lança sobre o homem de seu tempo, (vale mencionar que tanto O Estrangeiro como O Mito de Sísifo foram concebidos no período entre guerras) percebemos como ponto fulcral a apresentação de uma filosofia vital, visceral pautada na busca de uma vida autêntica. ${ }^{4}$

É apenas a partir da ascese entre o mundo ordinário e a revelação extraordinária, que a epifania absurda se faz presente. O homem absurdo é, para Camus, resultado da noção de estrangeirismo, daquele que por não nos conhecermos causa estranhamento, do ser que é lançado em um mundo onde nada se explica, onde levamos uma vida maquinal, como autômatos. Nessa suspensão, proporcionada por tal precariedade da existência, notamos que a autenticidade da vida está intimamente ligada à ideia de uma vida notável, digna e genuína; sendo necessário, portanto, certa customização da existência, movimento cujo ímpeto criativo mostra-se indispensável.

O ensaio, O Mito de Sísifo, ilustra a narrativa literária O Estrangeiro, Sísifo, figura central no primeiro é encarnado por Meursault, protagonista e narrador do segundo. Ambos versam de forma metafórica (representação, figuratividade, intercambiação de sentidos) sobre o momento que a humanidade estava atravessando, a Segunda Guerra Mundial. A insanidade reinava nesse período aonde a exacerbação da técnica conduzira o homem a sua quase autodestruição.

É justificável tal sentimento absurdo apontado pelo autor. A razão (nos referimos aqui da chamada razão técnica ou razão instrumental) lançara o homem nessa seara tingida com sangue, quanto a este ponto o autor pontua que "sempre se pensa erroneamente que a noção de razão tem um sentido único. Na verdade, por mais rigoroso que seja sua ambição, o conceito não deixa de ser movediço como os outros" (CAMUS, 2010, p.60). A ideia de razão para o contexto tratado pelo autor está relacionada com os "avanços" instrumentais proporcionados pela indústria

\footnotetext{
${ }^{4} \mathrm{Na}$ visão camusiana, compreendemos que a vida autêntica é a vida do absurdo, a sua aceitação, com a miséria e o flagelo e as angustias da própria vida do homem. Aceitar o desemparo, a vida em si.
} 
bélica, a mesma tecnologia que produz medicamentos para a cura de diversas doenças também construiu a bomba de hidrogênio, por exemplo. Camus lança mão de uma questão fundamental no seu pensamento, refletindo sobre a vida, o homem absurdo desenvolve uma dada sensibilidade existencial e se coloca diante da questão central para uma metafísica existencial/ontológica: A questão do suicídio. Quanto à crítica ao próprio fazer filosófico e, portanto, a tradição e seus equívocos Camus pontua que

Só existe um problema filosófico realmente sério: é o suicídio. Julgar se a vida vale ou não vale a pena ser vivida é responder à questão fundamental da filosofia. O resto, se o mundo tem três dimensões, se o espírito tem nove ou doze categorias, aparece em seguida. São jogos. É preciso, antes de tudo, responder. E se é verdade como pretende Nietzsche, que um filósofo, para ser confiável, deve pregar com o exemplo, percebe-se a importância dessa resposta, já que ela vai preceder o gesto definitivo (CAMUS, 2010, p.23).

O existencialismo lança o ser que se manifesta no ente humano na dissonância proposta pela desarmonia que o absurdo propõe. O absurdo como uma melodia inaudita, um descompasso tácito contido no próprio ordinário. No torvelinho filosófico proposto por Camus temos, em primeiro plano, a questão do suicídio como tema central, posto que a noção de humanidade até então empregada ruíra, e os valores propostos pelos sistemas racionalmente fundados como o iluminismo estavam em cheque. A claridade é a metáfora utilizada por Camus para colocar tal problema. Uma inadequação ${ }^{5}$ ontológica entre o homem e o mundo.

Meursault, em $O$ Estrangeiro, é levado pelas circunstâncias que a vida the impõe de modo autômato, como se não possuísse consciência de sua própria existência: vai ao velório de sua mãe; tem um caso amoroso com Marie; mata um árabe em uma praia aparentemente sem motivação. Percebido como um ser que transita pela vida de forma apática, sem revelar grandes emoções. No enredo, Camus nos apresenta uma instancia trágica da existência. Essa monotonia representada por Meursault foi vivida por Camus. Muito do que é visto como ficcional se confunde com o real. Não existem parâmetros seguros para valorar tais conceitos. A figuração metafórica proposta pelo autor remete a pulsões que o homem no seu

\footnotetext{
${ }^{5} \mathrm{O}$ que é essa inadequação? Fugir desse modelo de racionalidade em que o homem é consciente, dotado de valores estipulados pela própria razão que coisifica e rotula o indivíduo a fim de manipulálo. Tudo que está fora desse padrão e tido como alienado.
} 
dia a dia. O estranhamento é fruto da insuficiência de ordenação, a tragicidade é marca predominante em uma existência pautada na própria vida, esta como cativeiro, como exilio onde o estranhamento do estrangeiro está trancafiado. A condição humana comporta tal necessidade metafísica. Daí Camus apontar que:

\begin{abstract}
Um mundo que se pode explicar mesmo, com raciocínios errôneos, é um mundo familiar. Mas num universo repentinamente privado de ilusões e de luzes, pelo contrário, o homem se sente um estrangeiro. É um exilio sem solução porque está privado de uma pátria perdida ou da esperança de uma terra prometida. Esse divórcio entre o homem e a sua vida, o ator e seu cenário é propriamente o sentimento absurdo. (Camus, 2010, p.20)
\end{abstract}

Desterro, a própria vida é a pátria, ou melhor, o sentido da vida é o lugar comum do homem, ser apátrida, nesse caso, é perder o sentido desta, a metafisica é posta em cheque porque nos deparamos com uma filosofia vitalista que nega o além, que se manifesta na homem carne, no homem mundo, o lá é aqui, sem estar em conexão, o estranhamento e a absurdidade são a pele da existência, sentido a alma.

O homem vive esse desamparo, mas tem de retomar as rédeas de sua própria existência partindo de uma consciência prometéica, ou seja, iluminada ou esclarecida como pensava Kant ${ }^{6}$. A vida é algo que se ressignifica a cada passo do tempo, o peso do existir é gerado por essa angustia, Camus percebe que há um certo mistério que tende a nos levar a dualismos, a pensar na possibilidade de extramundo de vidas além, de negações, portanto, da vida presente. Esperança de outra vida que é preciso "merecer, ou truque daqueles que vivem não pela vida em si, mas por alguma ideia que a ultrapassa, sublima, Ihe dá um sentido e a trai" (CAMUS, 2010, p. 22). Pensamento contido no projeto nietzschiano, quando este propõe que o nilismo seria esse esvaziamento e aposta no nada, que caucionaria as potencialidades que a vida carrega consigo. A atitude do Homem absurdo seria uma revelia, esse absurdo abismal, e despertaria tal homem a outra conduta diferente do suicídio perante essa premissa: conduziria a uma existência potente guiada pela intensidade e lucidez, condição humana por excelência, não sobre-humana.

\footnotetext{
${ }^{6}$ Cf. Kant, Immanuel. Resposta à pergunta o que é o esclarecimento? Texto fundamental para compreensão de uma defesa da doutrina da Razão.
} 
Camus lança mão da absurdidade contida na existência da personagem Meursault, como meio de demostrar $O$ vazio de sentido que 0 homem contemporâneo experimentara na primeira metade do século XX. A metáfora do estrangeiro nesta conjuntura nos revela não apenas a intenção de compreendermos o desenlace das relações humanas durante os impasses existenciais presentes no século $\mathrm{XX}$, mas de refletirmos sobre o próprio sentimento de alheamento sentido pelo homem em toda sua trajetória, todavia que nesse período se apresentava de modo agudo.

Uma das principais características da contemporaneidade, é estar atravessada por valores complexos, quebra de paradigmas antes fixistas e estáticos, enquanto valores preestabelecidos, que até então sustentavam o homem moderno. $\mathrm{Na}$ filosofia camusiana tal perspectiva se mostra de forma latente. O Estrangeiro é explicado pelo Mito de Sísifo, literatura e filosofia se confundem, se espelham, e se atravessam. Meursault vive a proposta camusiana, representa o castigo dado a Sísifo, que tem como castigo rolar, infinitamente uma pedra até o topo de uma colina e em seguida deixá-la rolar initerruptamente, assim como Meursault é condenado a viver um vazio existencial. Podemos comparar a angustia de Meursault a de Sísifo, ambos foram condenados a uma existência precária, a uma liberdade absurda, "Os deuses condenaram Sísifo a empurrar incessantemente uma rocha até $\mathrm{O}$ alto de uma montanha, de onde tornava a cair por seu próprio peso. Pensaram, com certa razão, que não há castigo mais terrível que o trabalho inútil e sem esperança (CAMUS, 2010, p. 137).

Quando pensamos no crime cometido por Meursault somos levados a pensar nas circunstâncias: no sol, na arma que carregava, no árabe, etc. o disparo é maquinal, coisa do hábito. Meursault não joga o jogo da moral usualmente concebida a saber a moral nascida com a filosofia kantiana, talvez por isso é condenado à morte, não dissimula suas ações, vive à custa de sua própria existência, a moeda mais valiosa da vida: "tenho visto pessoas bem moralistas agindo errado e todos os dias comprovo que a honestidade não precisa ser provada onde está a imoralidade em se acender um cigarro, em ter uma relação amorosa, em aceitar um copo de café com leite?" (CAMUS, 2009, p. 79). Esses são argumentos utilizados contra Meursault, elementos 'significativos' para sua condenação. 
Um homem absurdo é aquele que percebe a inevitabilidade da vida de modo natural, que não projeta seus desejos em um futuro improvável. Percebe sua finitude, não busca glória alguma. Vivencia os fenômenos que a vida comporta sem tentar compreender sua plenitude, posto que o tudo é muito e contamos com variadas lentes para tentar enxergar a vida e suas contingências. Embarcar na vida significa aceitar o acordo, às vezes tácito, com o absurdo que esta carrega, sustenta o peso da desmedida, se lança no desconhecido, na angustia, sem ao menos tentar explicá-la. Contudo não a deixa de vivenciar. O homem é uma essência bruta lançada no mundo, uma possibilidade finita de uma impossibilidade, reflexo da fragilidade de existir, "o absurdo existencial nasce desse confronto entre o apelo humano e o silencio irracional do mundo". (CAMUS, 2010, p. 41). Faz-se necessário dar uma resposta a vida. $O$ absurdo é uma desmedida, desequilíbrio. Produto de uma hybris. Contudo a vida é irrestaurável, sem solução, viver é incurável. É necessário operar um eterno retorno do absurdo. A crítica camusiana está para além do simples maniqueísmo entre bem e mal. A literatura nesse caso se apresenta como um retrato falado, tal imagem retrata a miséria humana, a falta de sentido, o salto no nada, "viver é fazer que o absurdo viva. Fazê-lo viver é antes de tudo contemplá-Io" (CAMUS, 2010, p.63). A trilogia do absurdo faz parte da primeira parte do sistema filosófico de Camus, contempla, como podemos notar, a noção de absurdidade. Visto que:

Dar voz a infelicidade comum da condição humana, revitalizar o valor da vida humana singular em meio ao niilismo cego, ao silêncio das ideologias, à diluição dos indivíduos pelas burocracias de estado e à violenta insensibilização provocada pelo horror da história na primeira metade do século $\mathrm{XX}$, dominada pelas pseudo-fatalidades do progresso, da guerra, da "justiça" e da realpolitik: este é o objetivo filosófico que paira, afinal, no conjunto da primeira fase da obra literário-filosófica de Camus.(GERMANO, 2008, p. 330)

\section{O JULGAMENTO DE UM HOMEM ABSURDO}

O estranhamento do estrangeiro é caracterizado pela ruptura como os valores prefixados por uma cultura estacionária, estática, e por tal perspectiva podemos situar a conduta de Mersault estando à margem do convencional, do esperado. Com a metáfora do estrangeiro percebemos a intenção do olhar camusiano em representar o lugar do ser no mundo, este, o estrangeiro, como sendo essa 
consciência que foi lançada em um mundo desconhecido, para além das simples limitações topográficas.

Somos compostos não apenas por um sujeito, mas por subjetividades que se coadunam no ser por intermédio da alteridade. Outro é parte minha, a esse sentimento denominamos empatia, quando somos capazes de nos projetarmos no outro. Contudo nos vem uma questão: será que demostramos de dor unívoca nossas emoções? Sabemos que os fundamentos morais se arrastam por séculos a fio, diferentemente de posturas éticas, que se reconstroem a cada instante. Meursault é um homem que vive uma vida simples e solitária, age às vezes de forma ingênua até. Suas atitudes são consideradas estranhas, ele é um estrangeiro em sua própria vivência, e esse ar de apatia que toma é fruto desse estranhamento existencial, contudo carrega um espírito irrequieto, questionador. Ecos de Sísifo reverberam na vivência de Meursault, "não sei se este mundo tem um sentido que o ultrapassa. Mas sei que não o conheço, esse sentido é que por hora me é impossível conhece-lo" (CAMUS, 2010, p.63).

$\mathrm{Na}$ primeira parte da Narrativa de $\mathrm{O}$ estrangeiro, percebemos que todas as personagens são nomeadas, humanizadas: Raymond, Meursault, Marie, Salamano, Céleste. Os atos do protagonista narrador são vistos como estranhos, esquisitos, mas são aceitos. Contudo sua apatia é notada e fica na lembrança dos outros personagens. Já na segunda parte, as personagens se apresentam de forma desfigurada, desumanizadas. Descaracterizados e despidos em um ambiente onde seria julgado imoralmente, não um homem, mas uma coisa. Numa ritualística onde a "verdade" é construída a partir de preceitos e premissas pautadas em uma retórica hedionda e maquinal, "coisa do hábito".

Já no primeiro parágrafo da narrativa encontramos pistas da intensão de Camus com esse personagem, da apatia que este carrega, do estranhamento quanto a si mesmo. Ao receber a informação que sua mãe está morta, "Hoje, mamãe morreu. Ou talvez ontem, não sei bem. Recebi um telegrama do asilo: "sua mãe faleceu. Enterro amanhã. Sentidos pêsames”. Isso não esclarece nada. Talvez tenha sido ontem" (CAMUS, 2009, p.07). Trecho antológico desta produção camusiana. Pedra inaugural da filosofia do absurdo. Meursault é uma personagem que está imerso no seio da vivência absurda. Como no Amor Fati nietzschiano, aceita a vida em sua plenitude e aceita o os desdobramentos, mesmo que trágicos, que a vida impõe. Ele não joga o jogo da moral de sua época (e possivelmente do 
momento presente). Transvalora, subverte o comportamento coisificado que se espera do homem de seu tempo. De um tempo de guerra. Tal comportamento extra moral custa-lhe a vida:

O comportamento de Meursault constrange as pessoas porque, de certa forma desmascara a ficção do mito coletivo e a hipocrisia que a exprime: o amor filial como um dado naturalmente humano. Ele tem sua forma própria de manifestar afeto por sua mãe. Forma que não coincide com aquela dominante na sociedade em que vive, perante a qual é um estranho, um estrangeiro (CARVALHO, 2009, p. 154).

O ponto fulcral da narrativa está contido no momento em que Meursault mata um árabe em uma praia perto do Marengo. Até então vivera como um homem livre, usufruindo de sua liberdade, apesar de seu comportamento causar estranhamento aos demais. Vive um relacionamento amoroso com Marie, que em um determinado ponto pergunta se ele a ama, e na narrativa:

À noite, Marie veio buscar-me e perguntou se eu queria me casar com ela. Disse que tanto fazia, mas que se ela queria, poderíamos nos casar. Quis então saber se eu a amava. Respondi, como alias já respondera uma vez, que isso nada queria dizer, mas que não a amava (CAMUS, 2009, p. 45)

O fato é até então as ações de Meursault eram vistas como apenas indiferença. Contudo, depois da morte do árabe, em uma tarde quente, no décimo oitavo dia da narrativa, tudo se transforma. Com cinco tiros e motivação desconhecida, a primeira vista, ele mata um homem. A personagem nos relata que:

Pareceu-me que o céu se abria em toda a sua extensão deixando chover fogo. Todo meu ser se retesou e crispei a mão sobre o revólver. O gatilho cedeu, toquei o ventre polido da coronha e foi a, no barulho ao mesmo tempo seco e ensurdecedor, que tudo começou. Sacudi o suor e o sol. Compreendi que destruíra o equilíbrio do dia, o silencio excepcional de uma praia onde havia sido feliz. Então atirei quatro vezes ainda num corpo inerte em que as balas se enterravam sem que se desse por isso. E agora como se desse quatro batidas secas na porta da desgraça. (CAMUS, 2009, p. 63).

Desse ponto em diante todas as ações cometidas por Meursault se transfiguram, passa a ser incorporado ao seu inquérito atos cometidos por este que 
não estão ligados intimamente ao assassinato do árabe, como seu comportamento no funeral de sua mãe, "os investigadores tinham descoberto que eu "dera provas de insensibilidade no dia do enterro de minha mãe ter ido com Marie à praia, e em seguida assistir um filme cômico com esta, um filme de Fernandel." (CAMUS, 2009 p. 68). Bem como sua relação com Raymond. Tudo parece influir no ser veredito. Nesse ponto, o Estrangeiro se assimila a O Processo, de Franz Kafka, posto que ambos buscam entender seu processo e de como este se dará. $O$ ambiente lúgubre e uma atmosfera opressora são marcas nas duas narrativas ${ }^{7}$.

A vida de Meursault está para além de uma vida ilegítima, de acordo com as nuances que, naturalmente os percalços Ihe impõem. Aceita o jogo da vida, não da moral que está contida em seu tempo. Assim como Sísifo, Meursault é condenado por não se enquadrar na vida mecânica que the é imposta. O Homem absurdo, como já foi apontado acima, é aquele que subverte tais valorações impróprias, percebe que tem seu lugar na existência, mas paga pelo afastamento do convício "padrão" que o rodeia, que dita às normas comportamentais de seu tempo.

A advogado de Meursault percebendo que as premissas colocadas pelo promotor estão para além do fato ocorrido na praia, "afinal, ele é acusado de ter enterrado a mãe ou ter matado um homem?" (CAMUS, 2009, p. 100). As provas que motivam a condenação de narrador parecem estar mais ligadas a sua vida moral que a sua vida legal (juridicamente falando). Outro ponto importante é a descaracterização do relato de Marie, seu argumento é falseado, quando esta é posta ante ao júri, após ser questionada, " sentou-se, ainda no silencio geral. Mas, de repente, Marie irrompeu em soluços, dizendo que não era nada disso, que a coisa era diferente, que a obrigaram a afirmar o contrário do que pensava, que me conhecia muito bem e que eu não tinha feito nada de errado (CAMUS, 2009, p. 98). Nitidamente, podemos perceber que Meursault recebe um julgamento moral, é culpado por apatia, por não demonstrar sentimentos como os demais. A individualidade não cabe a essa existência fútil, vulgar. E quem não se enquadra a essa moral cínica é condenado, excluído e em alguns casos, morto. A justeza da justiça parece não coadunar-se com uma vida autenticamente ética.

\footnotetext{
${ }^{7}$ Vale ressaltar que Camus foi um assíduo leitor de Kafka, escreveu ensaios sobre a absurdidade contida nas narrativas Kafkianas. Inclusive conta na edição brasileira de O Mito de Sisifo um ensaio sobre tal tema.
} 
Tal personagem figura plenamente a crítica tecida por Camus em $O$ Mito de Sísifo, onde este, Sísifo, é condenado a uma vida miserável, ordinária, a rolar incessantemente sua pedra cotidiana pela infinitude a fio. A alegoria Camusiana faznos refletir sobre nossa própria existência. O mérito da obra esta contido na receptividade, no sentido dado pelo leito. "Em fim, o estrangeiro nos mostra que não há fronteira entre a criação literária e o ensaio filosófico, pois não ha fronteira entre o pensamento absurdo e uma literatura verdadeiramente absurda" (PIMENTA, 2014, p.90).

\section{CONSIDERAÇÕES FINAIS}

Camus apresenta certa radicalidade quanto a seu pensamento absurdo. $\mathrm{O}$ absurdo, apresenta-se ligado à solidão, enquanto que o seu ciclo seguinte, da revolta, está ligado à solidariedade. A absurdidade, portanto, parte de uma espécie de experimentação particular enquanto que a solidariedade está associada a um grupo de pessoas. Além de tentar compreender "o que é para Camus a absurdidade?" este estudo se propôs a tentar entender quais as contribuições que a literatura pode oferecer para a filosofia e vice-versa. Uma das principais críticas contidas nessas linhas diz respeito à chamada razão instrumental que, de certo modo, naturalizou a ideia de que o conhecimento técnico instrumental acarretaria em um dado avanço positivo para o homem, todavia acreditamos que a crítica camusiana deixa claro que esse movimento pode nos conduzir a resultados extremante danosos para a raça humana.

\section{REFERÊNCIAS}

CAMUS, Albert. O Estrangeiro. Tradução de Valerie Rumjanek. 30ª ed. Rio de Janeiro: Record, 2009.

. O Mito de Sísifo; tradução de Ari Roitman e Paulina Watch. $8^{\text {a }}$ ed. Rio de Janeiro: Record, 2010. . Le mythe de Sisyphe. Essais. Paris: Gallimard, 1965.

CARVALHO, José Jackson Carneiro de. Albert Camus: tragédia do absurdo. João Pessoa, Ideia, 2009. 
GERMANO, Emanuel Ricardo. O pensamento dos limites: contingência e engajamento em Albert Camus. Tese (Doutorado em Filosofia) - Faculdade de Filosofia, Letras e Ciências Humanas, Universidade de São Paulo. São Paulo, p. 468. 2007.

PIMENTA, Danilo Rodrigues. Filosofia e literatura em o estrangeiro de Camus. Revista Filosofia Capital: Brasília, vol. 9, n. 16, p. 83-91, jan/dez2014. Acesso: http://www.filosofiacapital.org/ojs-2.1.1/index.php/filosofiacapital em julho de 2017. 